\title{
Utilization of Waste Asphalt as an Additive in Mortars
}

\author{
Celik Sola Ozlem and Ozyazgan Cemil
}

\begin{abstract}
In this study waste asphalt was used in cement production to progress different types of civil engineering materials. For this purpose waste asphalt in three particle sizes was collected from Turkey were added to the Portland Cement (PC) and blended cement mixtures were prepared. After the chemical analysis and some physical properties of the cement mixtures (density, blaine, setting time), cements were produced by adding waste asphalt to PC. Waste asphalt was added to PC in ratios of $10 \%$ and $15 \%(\mathrm{wt} / \mathrm{wt})$ respectively. The mortars produced with different groups were tested for compressive strength values on 98 days according to European Standard (TS EN 196-1). The curing conditions were water, freeze-thaw and wet-dry. The results showed that mortars with waste asphalt had much higher compressive strength values than reference cement mortar for $Y$. In addition to these results, when particle size decreases, compressive strength increases in mortars with waste asphalt. After determining compressive strength results, XRD and SEM analysis were taken from No\#1, No\#4 and No\#7 due to the highest compressive strength results. The SEM analysis showed that the improvement in compressive strength by the waste asphalt was a physical effect.
\end{abstract}

Index Terms - Cement, SEM, waste asphalt, XRD.

\section{INTRODUCTION}

Waste asphalt has bitumen and it is hazardous waste. When it is utilized in a Project, harmful effects of its can be eliminated. In a study, it is with Zelic et al. [1], it is explained that addition of silica fume, because of the pozzolanic reaction, reduces the content of $\mathrm{CH}$ formed during hydration, which consequently reduces the leaching of lime and the content both of gypsum and ettringite during sulphate corrosion of mortars, and hence increases the mortar durability. When mineral additive is added in ratios of $40 \%$ and $60 \%$, compressive strength and durability properties of cement mortars is improved [2]. Mineral additives is also increased sulphate resistance [3] when they have fine particles give better compressive strength and sulphate resistance than coarse particles [4]. In another study is reported that mineral additives particularly slag have significantly reduced the expansions caused by sulfate attack [5] and the increase in the

mineral additive content caused a significant increase in the sulphate resistance of the mortars [6]. In this study, waste asphalt was utilized by cement production and its detrimental effect was reduced. Produced cement performance were

Manuscript received March 5, 2012; revised July 8, 2013. This work was supported by Scientific Research Projects Coordination Unit of Istanbul University, Project number 7681.

Celik Sola Ozlem is with Istanbul University, She is now with the Department of Civil Engineering, Avcilar Campus, Istanbul, Turkiye (e-mail: celik@istanbul.edu.tr).

Ozyazgan Cemil is with Kirklareli University, he is now with the Department of Civil Engineering, Karahidir Campus, Kirklareli, Turkiye (e-mail: cemil.ozyazgan@kirklareli.edu.tr). determined by compressive strength tests and after compressive strength tests, crushed samples were examined by XRD and SEM.

\section{MATERIALS AND METHODS}

Waste asphalt was obtained from in Turkey. The waste asphalt has three particle size. These are $0.425 \mathrm{~mm}(\mathrm{E})$, $0.180 \mathrm{~mm}(\mathrm{~F})$ and $0.075 \mathrm{~mm}(\mathrm{G})$. They are used in cumulative percent retained. PC was used Type II and it was obtained from SET Cement Factory. Cement samples were manufactured by waste asphalt adding to Portland cement. It was added to the PC in the ratios of 10 and $15 \%$ (wt/wt). The mixing ratios are given in Table $\mathrm{I}$. The chemical and some physical properties of cement mixtures used in experiments are presented in Table II and Table III respectively.

TABLE I : MiXTURE NO AND MiXING RATIOS OF MORTARS

\begin{tabular}{cc}
\hline \hline Mixture no & Mixture ratios \\
\hline 1 (Reference) & $\% 100 \mathrm{PC}$ \\
\hline 2 & $\% 90 \mathrm{PC}+\% 10 \mathrm{E}$ \\
\hline 3 & $\% 90 \mathrm{PC}+\% 10 \mathrm{~F}$ \\
\hline 4 & $\% 90 \mathrm{PC}+\% 10 \mathrm{G}$ \\
\hline 5 & $\% 85 \mathrm{PC}+\% 15 \mathrm{E}$ \\
\hline 6 & $\% 85 \mathrm{PC}+\% 15 \mathrm{~F}$ \\
\hline 7 & $\% 85 \mathrm{PC}+\% 15 \mathrm{G}$ \\
\hline \hline
\end{tabular}

\section{A. Preparation and Testing of Cement Mortar Samples}

The mortars prepared according to TS EN 196-1. The cement mortars prepared were put into $4 \times 4 \times 16 \mathrm{~cm}$ moulds with three cells. After preparing cement mortar samples in mould, they were stored in a moisture room under $20 \pm 1{ }^{\circ} \mathrm{C}$ and $90 \%$ humidity for 24 hours. After this procedure three curing conditions were applied to the samples. These are water, freeze-thaw and wet-dry. Samples were demoulded and stored under water at $20 \pm 1^{\circ} \mathrm{C}$ until testing for water curing conditions. After this procedure, compressive strengths were measured for 98 days at different curing conditions and recorded. 5 cycles were applied to the samples for freeze-thaw curing conditions. In a cycle, samples were stored under water with $\mathrm{MgSO} 4(13 \% \mathrm{w} / \mathrm{w})$ during one week. The other week, they dried in etuve. The last curing conditions in wet-dry, samples were also exposure 5 cycles. They were kept in water during a week and the other week on air.

\section{RESULTS}

\section{A. Compressive Strength}

Mixing ratios and compressive strength values of mortars 
produced by adding different size of waste samples were measured and their results were showed at Fig. 1. Compressive strength values decrease when increasing of waste asphalt percentages. In addition to this, when particle size of waste asphalt decreases, compressive strength values increases. Reference mortar has higher compressive strength value (57,2 MPa) (Sola-Celik et al., 2011) for water and wet-dry curing conditions, but all blended cement mortars have higher compressive strength value than reference mortar for freeze-thaw curing conditions. This is very important point.

TABLE II: CHEMICAL PROPERTIES OF CEMENT MIXTURES

\begin{tabular}{|c|c|c|c|c|c|c|c|c|c|}
\hline Mi & $\%$ & $\%$ & $\%$ & $\%$ & $\%$ & $\%$ & $\%$ & $\%$ & $\%$ \\
\hline Doxture & LOI & $\mathrm{SiO}_{2}$ & $\mathbf{A l}_{2} \mathbf{O}_{3}$ & $\mathrm{Fe}_{2} \mathrm{O}_{3}$ & $\mathrm{CaO}$ & MgO & $\mathrm{SO}_{3}$ & $\mathbf{K}_{2} \mathbf{O}$ & $\mathrm{Na}_{2} \mathrm{O}$ \\
\hline 1 & 8.38 & 17.53 & 4.73 & 2.08 & 61.87 & 1.16 & 3.42 & 0.75 & 0.35 \\
\hline 2 & 11.42 & 16.56 & 4.42 & 1.96 & 60.26 & 1.32 & 2.77 & 0.76 & 0.31 \\
\hline 3 & 11.43 & 17.38 & 4.55 & 1.99 & 59.15 & 1.37 & 2.49 & 0.77 & 0.33 \\
\hline 4 & 11.24 & 17.02 & 4.52 & 2.02 & 59.83 & 1.35 & 2.79 & 0.77 & 0.32 \\
\hline 5 & 13.18 & 16.12 & 4.31 & 1.92 & 59.61 & 1.38 & 2.21 & 0.75 & 0.38 \\
\hline 6 & 12.78 & 16.72 & 4.4 & 1.97 & 58.94 & 1.42 & 2.48 & 0.77 & 0.39 \\
\hline 7 & 12,67 & 16,84 & 4,5 & 1,97 & 58,53 & 1,46 & 2,85 & 0,78 & 0.4 \\
\hline
\end{tabular}

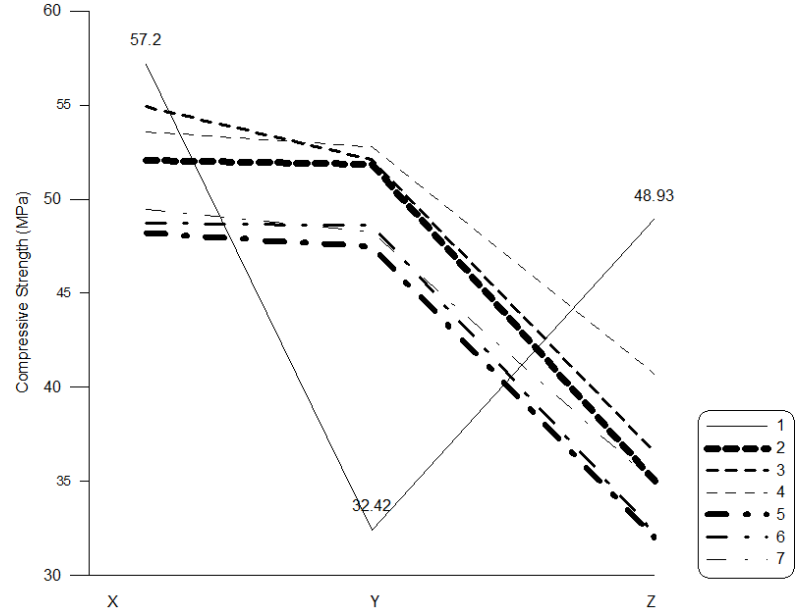

Fig. 1. Compressive strength results of mortars

TABLE III: SOME PhysiCAL PROPERTIES OF CEMENT MiXTURES

\begin{tabular}{cccccc}
\hline \hline $\begin{array}{c}\text { Mixture } \\
\text { no }\end{array}$ & $\begin{array}{c}\text { density } \\
\left(\mathbf{k g} / \mathbf{m}^{\mathbf{3}}\right)\end{array}$ & blaine $\left(\mathbf{m}^{\mathbf{2}} \mathbf{k g}\right)$ & water & demand $(\%)$ & \multicolumn{2}{c}{ Setting time } \\
\hline 1 & 3020 & 443.5 & 32.3 & 210 & 300 \\
\hline 2 & 2960 & 387.3 & 28.8 & 200 & 270 \\
\hline 3 & 2960 & 408.0 & 29.5 & 180 & 250 \\
\hline 4 & 2960 & 415.7 & 31.0 & 220 & 290 \\
\hline 5 & 2930 & 379.3 & 27.0 & 180 & 260 \\
\hline 6 & 2930 & 385.1 & 28.3 & 190 & 260 \\
\hline 7 & 2930 & 393.7 & 30.0 & 180 & 260 \\
\hline \hline
\end{tabular}

\section{B. XRD Results}

The samples were chosen as No\#1, No\#4 and No\#7 for XRD analysis. No\#1 is reference No\#4 and No\#7 have the highest compressive strength values in their percentage group. Therefore, cement reference sample, mortars with $\mathrm{G}$ particle size group were chosen for the analysis (Fig. 2-4). Analyze results showed that hydration products were mainly consisted of Quartz (Q), Calcium Hydroxide (CH), Calcite (C), Albite (A) and Microcline (M). When the XRD analyze of reference mortar is examined, the result showed that

reference mortar water peaks are very low level due to decrease of hydration reactions. There is a significant point at freeze-thaw conditions. XRD results of blended mortars showed that there wasn't any decrease on the peaks, but compressive strength results had risen very much. It can be explained that waste asphalt effects on durability properties of mortars isn't chemical. Particle size affected compressive strength properties directly.

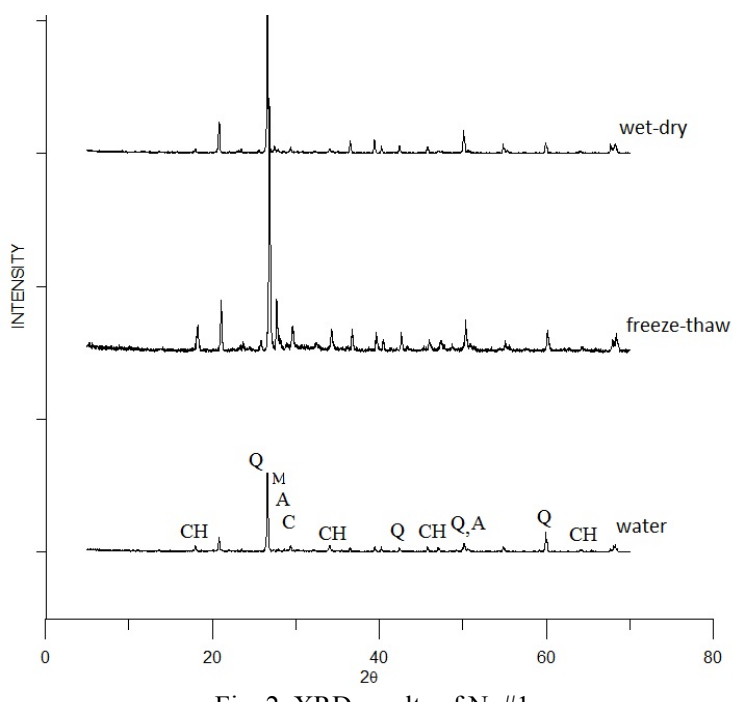

Fig. 2. XRD results of No\#1

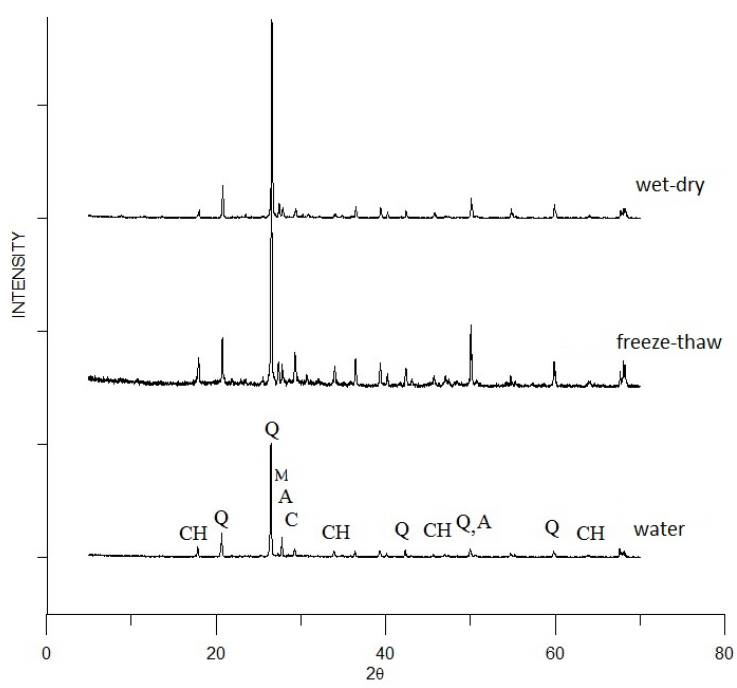

Fig. 3. XRD results of No\#4 


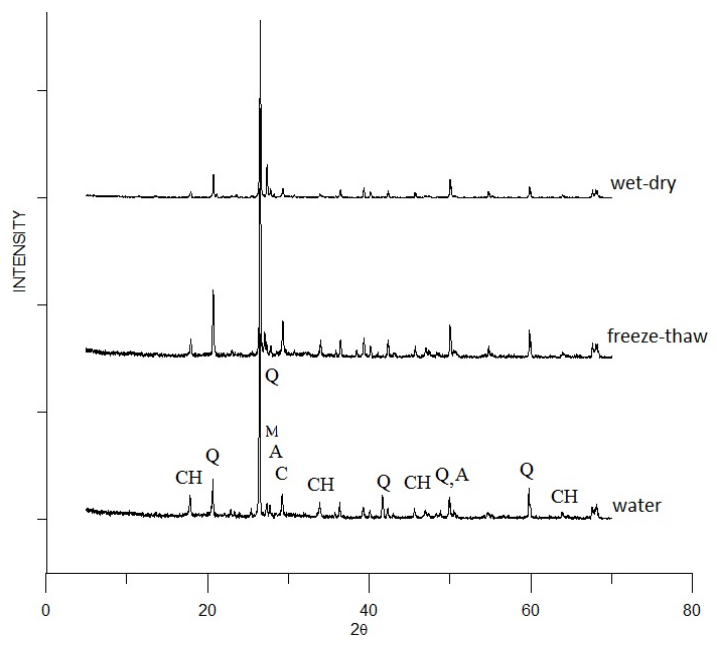

Fig. 4. XRD results of No\#7

\section{SEM Results}

The samples were chosen as No\#1, No\#4 and No\#7 for XRD analysis (Fig. 5-7). The results pointed out that SEM results correspond with compressive strength results. When freeze-thawconditions examine together for the SEM results, No\#4 has the densest microstructure. There are some porous structures and their results give less compressive strength values.

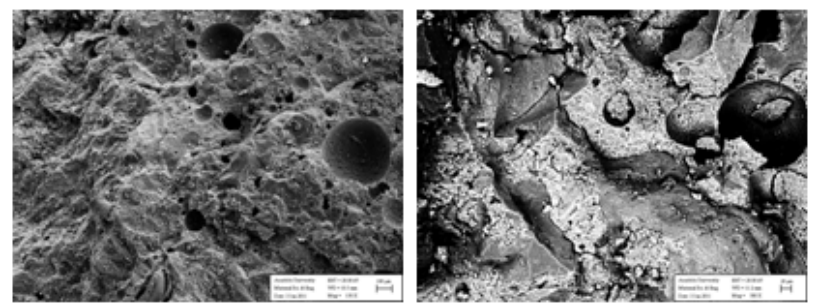

a) wet-dry

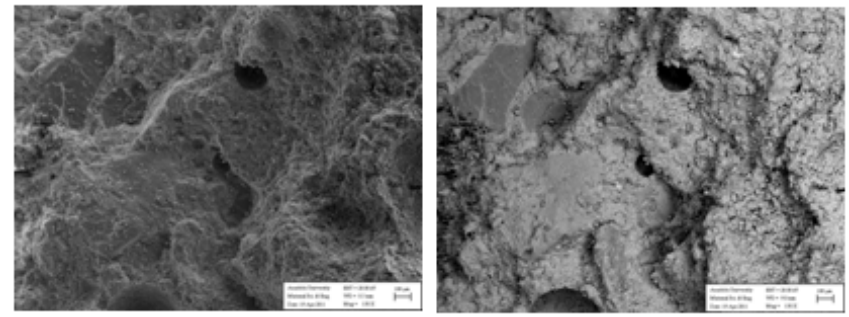

b) freeze-thaw

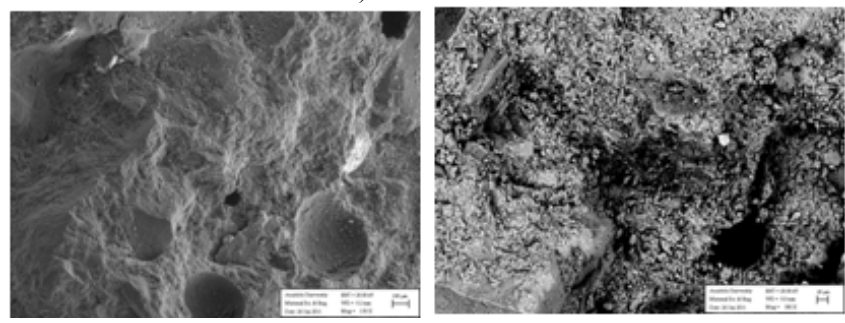

c) water

Fig. 5. SEM analyse of No\#1 a) wet-dry, b) freeze-thaw, c) water
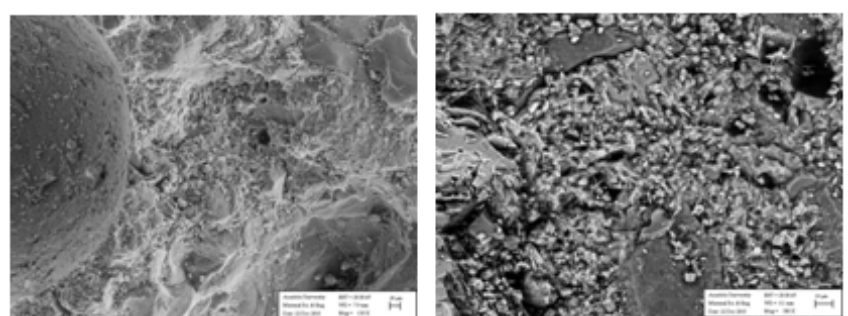

a) wet-dry

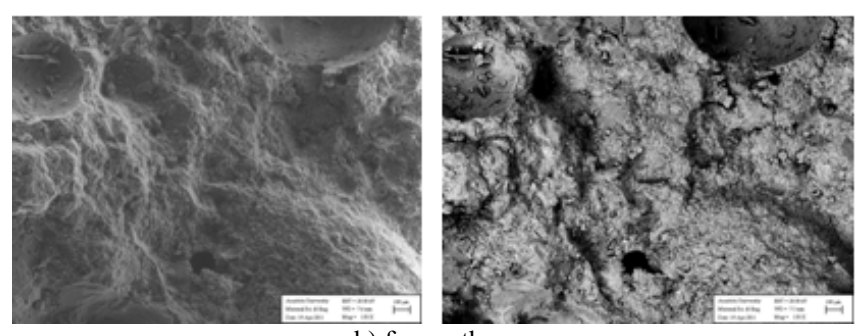

b) freeze-thaw

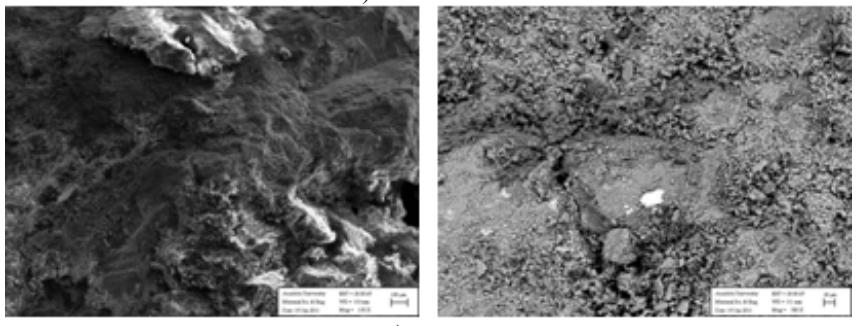

c) water

Fig. 6. SEM analyse of No\#4 a) wet-dry, b) freeze-thaw, c) water
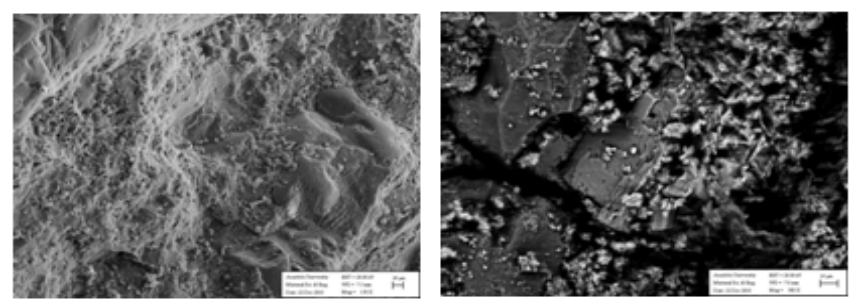

a) wet-dry

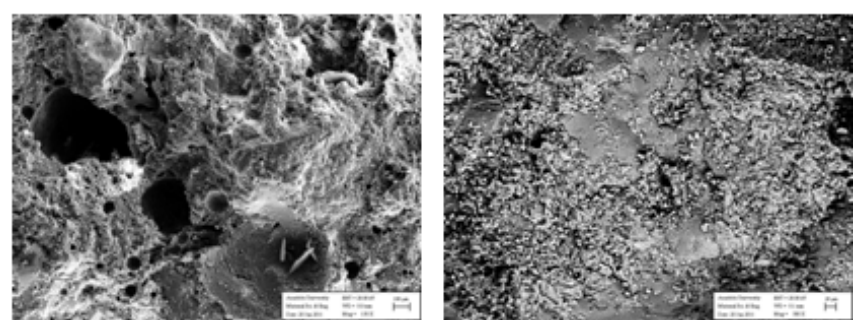

b) freeze-thaw

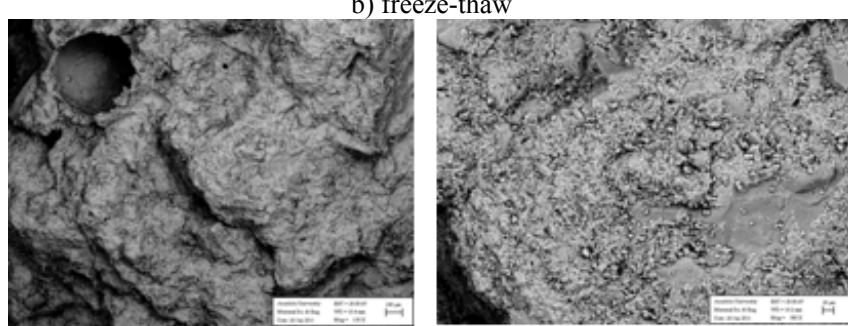

c) water

Fig. 7. SEM analyse of No\#7 a) wet-dry, b) freeze-thaw, c) water

\section{CONClusion}

The following conclusion can be drawn from the experimental results. Asphalt waste can be used as additions in alternative cement production. The best mechanical strength value is $57.2 \mathrm{MPa}$ and it was obtained from mortar which was prepared mix no 1 in 98 days. When waste asphalt ratio increases compressive strength values decreases. XRD results show that waste asphalt effects on durability properties of mortars aren't chemical but it is physical. Because waste asphalt particles were filled in the pore and compressive strength properties were affected directly. SEM results show that mortar with $10 \%$ waste asphalt has the densest microstructure and it has the highest freeze-thaw 
can be concluded that waste asphalt can be utilized in cement production, therefore preventing of environmental pollution can be contributed and its harmful effects can be reduced.

\section{ACKNOWLEDGMENT}

The authors would like to thanks to Istanbul Asphalt Factories and especially Head of Production Zafer Sola for supplying the waste. Set Cement Factory laboratory staff are gratefully acknowledged for their assistance with the experimental study.

\section{REFERENCES}

[1] J. Zelic, R. Krstulovi, E. Tkal, and P. Krolo, "Durability of the hydrated limestone-silica fume Portland cement mortars under sulphate attack," Cement and Concrete Research, vol. 29, pp. 819-826, 1999.

[2] Z. Wu and T. R. Naik, "Properties of concrete produced from multicomponent blended cements," Cement and Concrete Research, 2150, pp. 1-6, 2002.

[3] M. Uysal and M. Sumer, "Performance of self-compacting concrete containing different mineral admixtures," Construction and Building Mat., vol. 25, pp. 4112-4120, 2011.
[4] H. Binici, O. Aksogan, I. H. Cagatay, and M. Tokyay, "The effect of particle sizes distribution on the the properties of blended cements incorporating BBBFS and natural pozzolan (NP)," Powder Tech, vol.177, isue 3, pp.140-147, 2007.

[5] H. N. Atahan, "Use of mineral admixtures for enhanced resistance against sulfate attack," Construction and Building Materials, vol.25, issue 8, pp. 3450-3457, 2011.

[6] H. Binici, S. Kapur, J. Arocena, and H. Kaplan, "The sulphate resistance of cements containing red brick dust and ground basaltic pumice with sub-microscopic evidence of intra-pore gypsum and ettringite as strengtheners," Cement and Concrete Composites, vol.34, issue 2, pp. 279-287, 2012.

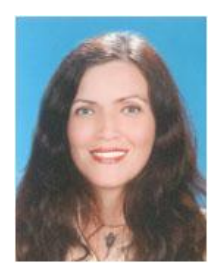

Celik Sola Ozlem was born in 1968, Trabzon, Turkiye. She got the B.Sc. and MSc. degree from Istanbul Tech. University, Chemical Eng. Dept., Istanbul University; $\mathrm{PhD}$. from Yildiz Technical University, Chemical Eng. Dept. Her subject area is "production of different types of construction materials "Istanbul Asphalt Factory (ISFALT), Istanbul. Her current job is asst. Prof. Dr. in Istanbul University.

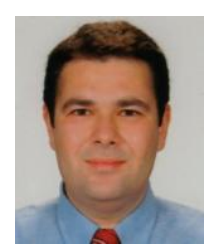

Ozyazgan Cemil was born in 1975, Gaziantep, Turkiye. $\mathrm{He}$ got B.Sc., MSc, and Ph.D. degree from Istanbul University, Civil Eng. Dept. His Subject area is "production of different types of construction materials" His current job is asst. Prof. Dr. in Kirklareli University. 